\title{
A new species of Hedruris Nitzsch, 1821 (Nematoda: Hedruridae) parasitic in the freshwater fish Oligosarcus jenynsii (Günther, 1864) (Characidae) from Argentina
}

\author{
María Alejandra Rossin · Juan Tomás Timi
}

Received: 5 April 2016/ Accepted: 28 September 2016

(C) Springer Science+Business Media Dordrecht 2016

\begin{abstract}
Nematodes belonging to genus Hedruris Nitzsch, 1821 (Nematoda: Hedruridae) were found in the stomach of the freshwater fish Oligosarcus jenynsii (Günther, 1864) (Characidae) from a shallow eutrophic lake in Argentina. Morphological comparisons with congeneric relatives showed that these nematodes belong to a new species, for which $H$. bifida n. sp. is proposed. Hedruris bifida n. sp. can be distinguished from its congeners by the following combination of characters: bifid deirids, absence of precloacal papillae and nine pairs of postcloacal papillae and non-mammillated eggs. The new species closely resembles Hedruris suttonae Brugni \& Viozzi, 2010, the only known species from Argentina; however, the bifid deirids in the new species and the distribution pattern of perianal spines in females clearly distinguish both species. Hedruris bifida n. sp. represents the second nominal species of the genus in Argentina and the eighth species described in the Neotropical region.
\end{abstract}

M. A. Rossin $(\varangle) \cdot$ J. T. Timi

Laboratorio de Ictioparasitología, Instituto de Investigaciones Marinas y Costeras (IIMIyC), Facultad de Ciencias Exactas y Naturales, Universidad Nacional de Mar del Plata-Consejo Nacional de Investigaciones Científicas y Técnicas (CONICET), Funes 3350, 7600 Mar del Plata, Argentina

e-mail: mrossin@mdp.edu.ar

\section{Introduction}

Members of the genus Hedruris Nitzsch, 1821 (Nematoda: Hedruridae) are absolutely unique among nematodes because females possess a retractable chitinised hook that is used for attachment to the host stomach wall, and males generally found coiled around female (Baker, 1986). The genus was erected by Nitzsch (1821) for $H$. androphora Nitzsch, 1821. At present, Hedruris includes 22 valid species and two species inquirendae, parasites of amphibians, reptiles and freshwater fishes distributed worldwide (Bursey \& Goldberg, 2000, 2007; Brugni \& Viozzi, 2010; Luque et al., 2010). Nine species of Hedruris have been described in the Neotropical region; five of these parasitising different species of amphibians: H. heyeri Bursey \& Goldberg, 2007; H. moniezi Ibáñez \& Córdoba, 1976; H. macronifer Schuurmans Stekhoven, 1952; H. juninensis Bendezú, 1976; and H. scabra Freitas \& Lent, 1941. However, males of $H$. scabra are unknown, and this species was considered a species inquirenda by Bursey $\&$ Goldberg (2000). The remaining four species are parasites of fishes: $H$. basilichtensis Mateo, 1971; $H$. orestiae Moniez, 1889; H. iheringi Pereira \& Vaz, 1931; and $H$. suttonae Brugni \& Viozzi, 2010. The last two species were described in fishes from Argentina, but $H$. iheringi was later considered a species inquirenda by Bursey \& Goldberg (2000), because males are unknown. Therefore, $H$. suttonae, a native parasite of fishes from Patagonian lakes, is the only valid species recorded in Argentina (Brugni \& Viozzi 2010). 
Oligosarcus jenynsii (Günther) (Characidae) is a common inhabitant of shallow eutrophic lakes in the Pampasic region of Argentina (Liotta, 2006). During a parasitological survey carried out on samples of $O$. jenynssi from a Pampasic shallow lake, fish were found to be infected by adult nematodes belonging to the genus Hedruris. These nematodes are described below as a new species of Hedruris.

\section{Materials and methods}

Specimens of Oligosarcus jenynsii from Lake Nahuel Rucá $\left(37^{\circ} 37^{\prime} \mathrm{S}, 57^{\circ} 26^{\prime} \mathrm{W}\right)$, Buenos Aires Province, Argentina, South America, were collected using trawler nets during March and December 2011. A total of 59 fishes (total body length 10-22 cm) were caught, transported to the laboratory and examined for parasites under a stereoscopic microscope.

A total of 32 (24 females and 8 males) specimens of an unidentified species of Hedruris were collected, fixed in $4 \%$ formaldehyde solution, transferred to $70 \%$ ethanol for storage, cleared in lactophenol, studied and measured under a light microscope. Drawings were made using a drawing tube. For scanning electron microscopy (SEM), specimens were dehydrated in a series of ethanol washes, dried in hexamethyldisilazane, coated with gold, and examined in a JEOL JSM 6460-LV SEM.

All measurements are in micrometres, unless otherwise indicated and are given as the range followed by the mean in parentheses. The typematerial was deposited in the Helminthological Collection of the Museo de La Plata (CHMLP), La Plata, Argentina.

\section{Family Hedruridae Railliet 1916 Subfamily Hedrurinae Chitwood \& Wehr 1934 Genus Hedruris Nitzsch 1821}

\section{Hedruris bifida n. sp.}

Type-host: Oligosarcus jenynsii (Günther) (Characiformes: Characidae).

Type-locality: Lake Nahuel Rucá $\left(37^{\circ} 37^{\prime} \mathrm{S}, 57^{\circ} 26^{\prime} \mathrm{W}\right)$, Buenos Aires Province, Argentina.

Type-material: Holotype, male (MLP-He coll. No. 7159), allotype, female (MLP-He coll. No. 7160) and paratypes, 2 males and 10 females (MLP-He coll. No. 7161).

Site in host: Females attached by hook to the stomach wall and males generally found encircling female. Prevalence: $25.42 \%$ (15 of 59 fishes infected). Intensity: 1-7 nematodes (mean 2.13 per fish). Mean abundance: 0.54 nematodes per fish.

Etymology: The specific epithet refers to the morphology of the deirids.

\section{Description (Figs. 1-23)}

General. Medium-sized nematodes, females larger than males, cuticle thick, with fine transverse striations. Cephalic end rounded (Figs. 1-4, 13-14), with 2 triangular lateral pseudolabia, supported by thick cuticular ridge, each bearing 1 amphid, pair of digitiform papillae and pair of lateral sessile papillae (Figs. 1, 3, 13-14). Dorsal and ventral lips large, supported by thick cuticular ridge, with 2 bifurcate projections extending posteriorly (Figs. 2, 14). Buccal cavity thin walled, oesophagus not clearly divided into muscular and glandular portions (Fig. 4). Deirids elongated and bifid at distal end and anterior to nerve-ring (Figs. 4, 5, 15). Excretory pore posterior to nerve-ring (Fig. 4). Female with typical sclerotised hook for attachment to host and male generally found encircling female (Figs. 9, 10).

Male [Based on 5 specimens.] Body length 6.4-10.0 (7.8) mm, maximum body width 160-300 (212). Pseudolabia 60-96 (83) long. Oesophagus 0.6-1.5 (1.1) mm long. Deirids 215-262 (249), neve-ring 225-232 (265) and excretory pore 307-510 (416) from anterior extremity. Posterior end of body spirally coiled. Caudal alae present, narrow, supported by caudal papillae (Figs. 6, 22). Precloacal papillae absent, 9 pairs of postcloacal papillae present, first 8 pairs subventral, last pair lateral (one specimen exceptionally presented 10 pairs on right side) (Figs. 6, 21, 22). Single pair of small phasmids present posterior to last subventral papillae (Fig. 6). Area rugosa with 8 ventral longitudinal ridges, extending 2.8-3.0 (2.9) mm from cloaca (Figs. 7, 22, 23). Spicules 207-227 (218) long, slender fused on its mid-length, curved in distal tip with lateral membranous expansions (Fig. 8). Gubernaculum absent. Tail 332-442 (378) long. 

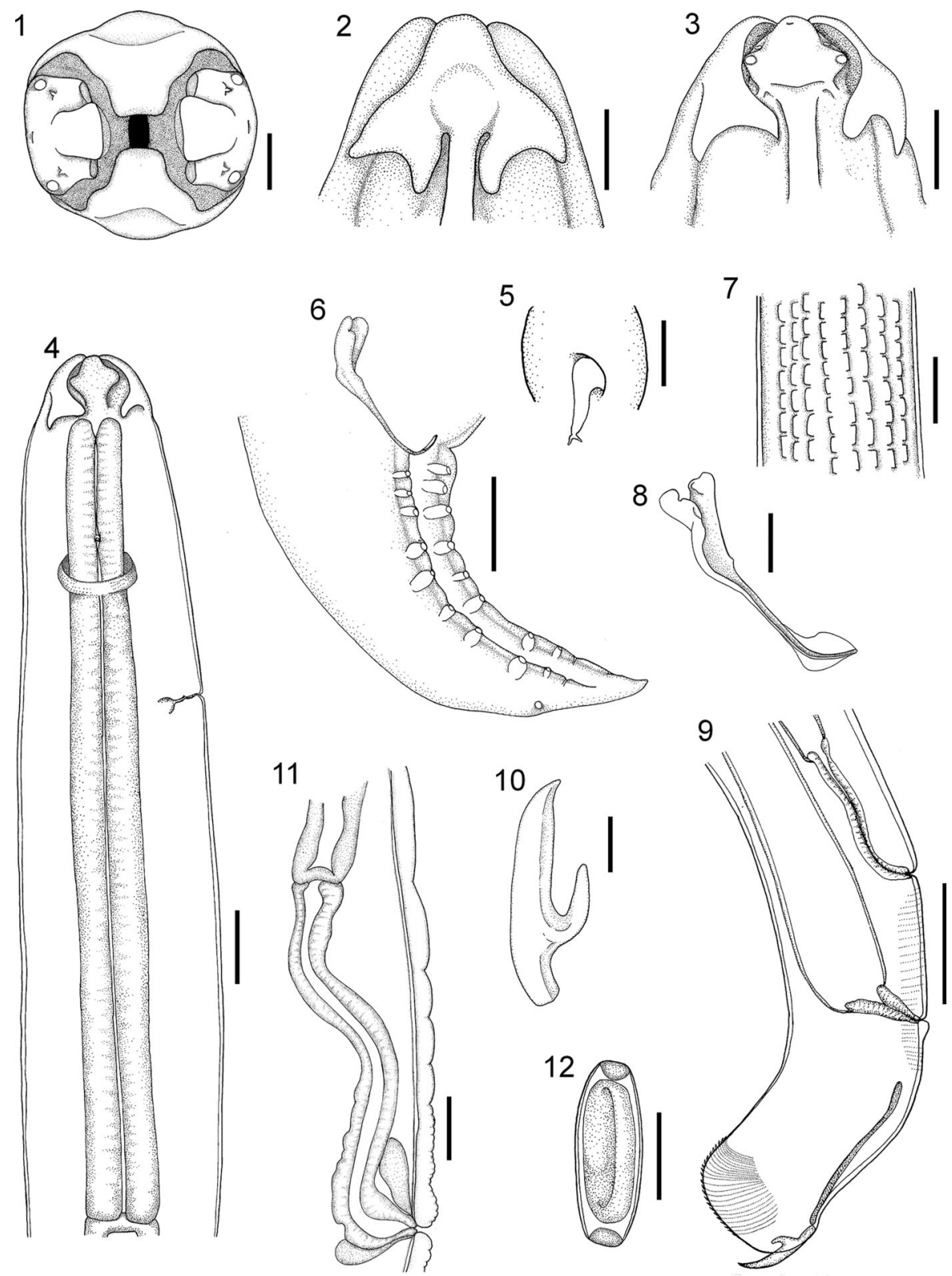

Figs. 1-12 Hedruris bifida n. sp. 1, Cephalic end, apical view; 2, Dorsal labia; 3, Lateral pseudolabia. 4, Anterior end, lateral view; 5, Deirid; 6, Tail of male, ventrolateral view; 7, Area rugosa, ventral view; 8, Spicule, subventral view; 9, Tail of female, lateral view; 10, Hook, lateral view; 11, Region of vulva, lateral view; 12, Egg. Scale-bars: 1, 12, $20 \mu \mathrm{m} ; 2,3,11,60 \mu \mathrm{m} ; 4,120 \mu \mathrm{m} ; 5,10 \mu \mathrm{m} ; 6,7,100$ $\mu \mathrm{m} ; 8,50 \mu \mathrm{m} ; 9,250 \mu \mathrm{m} ; 10,40 \mu \mathrm{m}$

Female [Based on 10 gravid specimens.] Body length 7.2-11.2 (8.8) mm, maximum body width 280-480 (362). Pseudolabia 100-16 (120) long. Oesophagus 1.0-2.1 (1.5) mm long. Deirids 250-362 (297). Nervering 250-367 (305) and excretory pore 425-650 (486) from anterior extremity. Vulva 187-328 (266) from anus, 537-845 (660) from caudal end (Fig. 9). Prodelphic, uterus occupying the entire body, filled with larvated eggs. Tail curved dorsally, 300-540 (400) long in specimens with fully-everted tail (Fig. 9). Caudal eversible prehensile structure (holdfast) armed with sclerotised hook, 137-212 (181) long, 

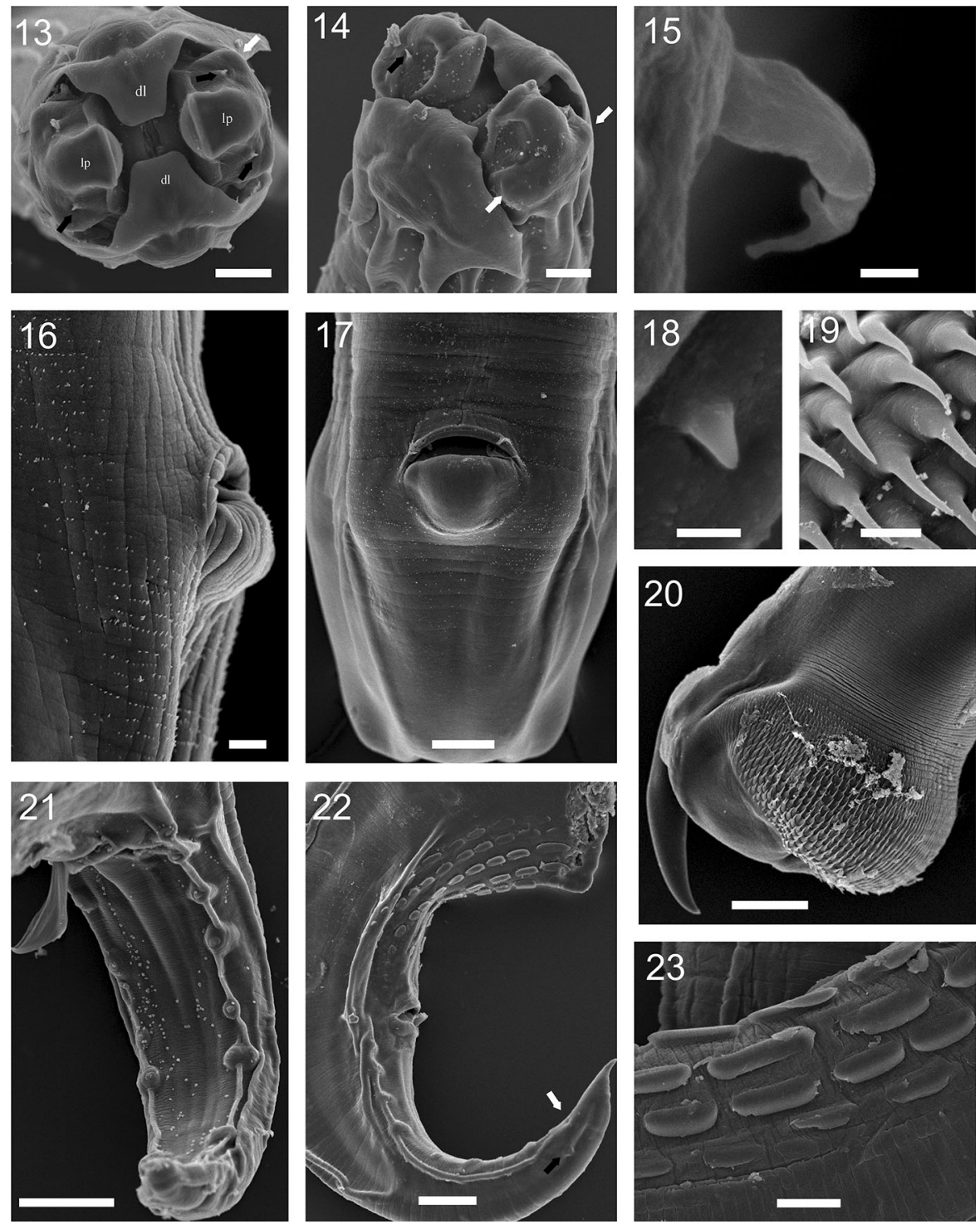

Figs. 13-23 Hedruris bifida n. sp. SEM micrographs. 13, Cephalic end, apical view (lp, lateral pseudolabia; dl, dorsal labia; black arrow, digitiform papillae; white arrow, lateral sessile papillae); 14, Cephalic end, subapical view; 15, Deirid; 16, Anal region, lateral view; 17, Anal region, ventral view; 18, Spines of anal area; 19, Spines of dorsal area; 20, Caudal end of female, with hook everted; 21, Caudal end of male showing caudal papillae, ventral view; 22, Caudal end of male showing precloacal surface, lateral view (black arrow, lateral papillae; white arrow, phasmids); 23, Detail of area rugosa surface. Scale-bars: 13-14, 23, $20 \mu \mathrm{m} ; 15,18,1 \mu \mathrm{m} ; 16,10$ $\mu \mathrm{m} ; 17,20-23,50 \mu \mathrm{m}$

bearing 2 lateral projections, 50-117 (103) long (Figs. 9, 10, 20). Holdfast mounted on accessory elongate sclerotised structure formed by 2 arms, 300-350 (326) long; both arms extending lateroventrally from hook base to anterior part of body, not reaching the anus (Figs. 9, 11). Caudal spines distributed in 2 areas, perianal and dorsal on tail tip (Fig. 9). Perianal area with irregular rows of sparse and small spines (Fig. 18) extending anteriorly to vulval area (Figs. 9, 16-17). Dorsal spiny area densely covered by large, sharply-pointed spines (Fig. 19), homogeneously distributed in transverse lines and decreasing in size anteriorly (Figs. 9, 20). Non-mammillated larvated eggs, 42-46 (44) long, 14-15 (15) wide, operculated at each end (Fig. 12). 
Remarks

Species of Hedruris are commonly distinguished by the number and distribution of the caudal papillae present in males and egg shape. The presence of postcloacal papillae only is a common feature of Neotropical species described to date (Bursey \& Goldberg, 2000), including the new species. Among them, Hedruris bifida n. sp. shares the presence of nine pairs of postcloacal papillae with $H$. basilichtensis, $H$. moniezi, $H$. orestiae and $H$. suttonae (see Mateo, 1971; Ibañez \& Córdova, 1976; Bursey \& Goldberg, 2000 Brugni \& Viozzi, 2010), whereas $H$. juninensis Bendezú, 1976 and H. mucronifer Schuurmans Stekhoven, 1952 have eight and seven pairs, respectively (Schuurmans Stekhoven, 1952; Bendezú, 1976).

Hedruris bifida $\mathrm{n}$. sp. differs from $H$. basilichtensis and $H$. orestiae by having longer spicules (207-227 vs 175-193 and 178-194 $\mu \mathrm{m}$, respectively), with $H$. orestiae having also smaller eggs (31-42 vs 44-46 $\mu \mathrm{m})$. Hedruris moniezi differs from the new species by the larger size of the hook (251-292 vs 137-212 $\mu \mathrm{m})$ and its accessory supports (575-582 vs 300-350 $\mu \mathrm{m})$ in females. Hedruris bifida n. sp. resembles $H$. suttonae, the only known species from Argentina, in most of its morphometric traits; however, the bifid deirids in the new species clearly distinguish both species; these in addition are located more posteriorly in $H$. bifida than in H. suttonae (250-362 vs 156-288 $\mu \mathrm{m}$ from anterior end). Moreover, the two species can be distinguished by the presence of a rectangular cuticular ridge at the base of pseudolabia in $H$. suttonae ( $v$ s absence in $H$. bifida) and by the pattern of the perianal spines. Indeed, $H$. bifida $\mathrm{n}$. sp. posesses an oval patch of sparse and small spines surrounding the anus and extending anteriorly to the level of the vagina, while in $H$. suttonae this patch is U-shaped and is composed by larger and densely and evenly distributed spines. The morphology of these ventral spines is also different, being blunt and smaller in the new species and sharply-pointed, with lateral protrusions in $H$. suttonae.

The presence of nine pairs of caudal papillae is also shared with the Palaeartic species $H$. androphora Nitzsch, 1821 and H. ijimai Morishita, 1926, parasites of tetrapods (Nitzsch, 1821; Morishita, 1926; Bursey \& Goldberg, 2000). However, both have mammillated eggs and the anterior pair of caudal papillae is precloacal in $H$. androphora and adcloacal in $H$. ijimai (Bursey \& Goldberg, 2000).

\section{Discussion}

Hedruris bifida $\mathrm{n}$. sp. is the eight nominal species described in the Neotropical region and the fourth in a fish host. Moravec (1998), stated that fishes are facultative hosts for Hedruris spp. since the presence of these parasites in fishes is a consequence of predation of the infected definitive (amphibians) or intermediate (crustaceans) hosts. However, despite post-cyclic transmission may occur between fishes, Brugni \& Viozzi (2010) considered that this is not the case for $H$. suttonae in galaxiid hosts, since amphibians are not components of the diet of these fishes, thus proposing fishes as true definitive hosts for hedrurids. The authors also based their conclusion on the high values of prevalence and intensity observed in galaxiids. This seems to be also the case of the new species, since no amphibians have been identified as prey items for O. jenynsii (see Escalante, 1983; Haro $\&$ Gutierrez, 1985). Indeed, with the description of the new species from a fish host, there are as many species of hedrurids parasitising amphibians as fishes in the Neotropics.

Acknowledgements We thank Dr. Norma Brugni and Dr. Gustavo Viozzi for gently providing specimens and SEM microphotographs of Hedruris suttonae.

Funding Financial support was provided by grants from Agencia Nacional de Promoción Científica y Tecnológica, Argentina (ANPCYT; PICT \# 2131-2010) and Consejo Nacional de Investigaciones Científicas y Técnicas (CONICET-PIP \# 112-20110100036).

\section{Compliance with ethical standards}

Conflict of interest The authors declare that they have no conflict of interest.

Ethical approval All applicable institutional, national and international guidelines for the care and use of animals were followed. Permit for fishing provided by Ministerio de Asuntos Agrarios de la Provincia de Buenos Aires, Argentina (Disposición 164, August 237th, 2012).

\section{References}

Baker, M. R. (1986). Revision of Hedruris Nitzsch (Nematoda: Habronematoidea) from aquatic vertebrates of North America. Canadian Journal of Zoology, 64, 1567-1572.

Bendezú, L. S. (1976). Nueva especie del genero Hedruris Nitzsch, 1821 Nematode Parasito de Batrachophrynus 
brachydactylus Peters, 1873. Revista Ciencias Universidad Nacional Mayor de San Marcos, 70, 45-51.

Brugni, N. L., \& Viozzi, G. P. (2010). A new hedrurid species (Nematoda) from galaxiid fishes in Patagonia (Argentina), and infection of amphipods as intermediate host. Journal of Parasitology, 96, 109-115.

Bursey, C. R., \& Goldberg, S. R. (2000). Hedruris hanleyae n. sp. (Nematoda: Hedruridae) from Hemidactylus garnotii (Sauria: Gekkonidae) from the Cook Islands. Oceania. Journal of Parasitology, 86, 556-559.

Bursey, C. R., \& Goldberg, S. R. (2007). New species of Hedruris (Nematoda: Hedruridae), Anuracanthorhynchus lutzi (Hamann, 1891) n. comb. and other helminths in Lithobates warszewitschii (Anura: Ranidae) from Costa Rica. Caribbean Journal of Science, 43, 1-10.

Escalante, A. (1983). Contribución al conocimiento de las relaciones tróficas de peces de agua dulce del área platense II. Otros Tetragonopteridae. Limnobios, 2, 379-402.

Haro, J., \& Gutierrez, M. (1985). Alimentación de Oligosarcus jenynsii (Günther) (Pisces, Characidae) en el lago San Roque (Córdoba, Argentina). Revista de la Asociación de Ciencias Naturales del Litoral, 16, 227-235.

Ibáñez, N. H., \& Córdova, E. B. (1976). Quatro especies nuevas de nematodos del Sur del Perú y redescripción de Hedruris orestiae Moniez, 1889. Memorias do Instituto Oswaldo Cruz, 74, 231-254.

Liotta, J. (2006). Distribución geográfica de los peces de aguas continentales de la República Argentina. ProBiota, Serie Documentos $\mathrm{N}^{\circ} 3$, FCNyM, UNLP. Buenos Aires, 701 pp.

Luque, J. L., Vieira, F. M., Herrmann, K., King, T. M., Poulin, R., \& Lagrue, C. (2010). New evidence on a cold case: trophic transmission, distribution and host-specificity in Hedruris spinigera (Nematoda: Hedruridae). Folia Parasitologica, 57, 223-231.

Mateo, C. E. (1971). Nematodes de peces del Lago Titicaca. II. Hedruris basilichtensis, nueva especie de la familia $\mathrm{He}$ druridae Raillet, 1916. Revista Villareal, 1, 81-84.

Moravec, F. (1998). Nematodes of freshwater fishes of the Neotropical region. Prague: Academia, 464 pp.

Morishita, K. (1926). Studies on some nematode parasites of frogs and toads in Japan, with notes on their distribition and frequency. Journal of the Faculty of Science Imperial University of Tokyo, 1, 1-32.

Nitzsch, C. L. (1821). Ascaris. Allgemeine Encyclopadie der Wissenschaften and Kunste, 6, 44-49.

Schuurmans Stekhoven, J. H. (1952). Nematodos parasitarios de anfibios, pájaros y mamíferos de la República Argentina. Acta Zoologica Lilloana, 10, 315-400. 